\title{
MULTI-OBJECTIVE TIME-COST OPTIMIZATION USING COBB-DOUGLAS PRODUCTION FUNCTION AND HYBRID GENETIC ALGORITHM
}

\author{
Zhigang SHEN ${ }^{\mathrm{a}, \mathrm{b}}$, Ashkan HASSANI ${ }^{\mathrm{b}}$, Qian SHI \\ ${ }^{a}$ Department of Civil and Urban Engineering, New York University, 6 MetroTech Center, \\ RH408, Brooklyn, 11201 New York, USA \\ ${ }^{b}$ The Durham School of Architectural Engineering and Construction, University of Nebraska - Lincoln, \\ 113 NH, Lincoln, NE 68588-0500, USA \\ 'School of Economics and Management, Tongji University, Siping Road 1239, 200092 Shanghai, P. R. China
}

Received 23 Oct 2012; accepted 16 Apr 2013

\begin{abstract}
Existing research on construction time-cost tradeoff issues rarely explore the origin of the crashing cost. Crashing cost function was either assumed without much justification, or came from historical data of some real projects. As a result the conclusions of the papers can hardly be used to guide allocations of labor and equipment resources respectively. The authors believe Cobb-Douglas function provides a much-needed piece to modeling the cost functions in the construction time-cost tradeoff problem during the crashing process. We believe this new perspective fills a gap of existing time-cost tradeoff research by considering project duration, labor and equipment cost as parameters of the CobbDouglas production function. A case study was presented to show how the proposed framework works. Our conclusion is that introducing Cobb-Douglas function into time-cost tradeoff problem provides us extra capacity to further identify the optimal allocations of labor and equipment resources during crashing.
\end{abstract}

Keywords: Cobb-Douglas, production function, crashing, time-cost tradeoff, hybrid genetic algorithm.

\section{Introduction}

Time-cost tradeoff problem (TCTP) has been intensively studied in construction scheduling research (Feng et al. 1997, 2000; Hegazy 1999; Ng, Zhang 2008) to find out the best solutions in terms of minimizing the cost while shortening the project duration. Many different algorithms and assumptions were used in searching the best solutions which are explained in detail later.

Despite many existing researches on TCTP, very little study was found in exploring or explaining the source or the origin of the cost increase during activity crashing. Instead, in many studies, the cost functions associate with crashing were assumed, or based on historical data, or based on simulation results. Being able to explain quantitatively where the increased crashing costs come from is important to better understand the theoretical fundamental of TCTP.

There has been a lack of theoretical base to model the cost functions associated with activity crashing. Evensmo and Karlsen (2008) were among the few researchers tried to explain the origin of cost increase during activity crashing. However, in their study they only discussed the causes due to labor input changes. A significant limitation in their approach is the lack of consideration of changes of equipment inputs during crashing activities.

Considering many construction crews are composed of both labor and equipment, it is necessary to identify or develop new models to consider both labor and equipment changes during the activity crashing procedure, so we can more accurately modeling the crashing cost functions.

Cobb-Douglas production function (CDPF) (Eqn (1)) (Cobb, Douglas 1928; Varian 1992) has been widely used in research on economics (Meeusen, van den Broeck 1977; Dennis et al. 2010), technology progress (Sircar, Choi 2009), and productivity (Banker, Natarajan 2008; Pendharkar et al. 2008):

$$
Q=A . . L^{\beta} \cdot K^{\alpha},
$$

where: $Q$ - total production; $L$ - labor input; $K$ - capital/ equipment input; $A$-technology; $\alpha$ and $\beta$ are the output elasticity of labor and capital respectively.

In particular, CDPF models production, labor inputs, equipment/capital inputs and technology efficiency in a very elegant formation, which can be used to explain many types of production activities. Some important features of

Corresponding author: Zhigang Shen

E-mail:shen@unl.edu 


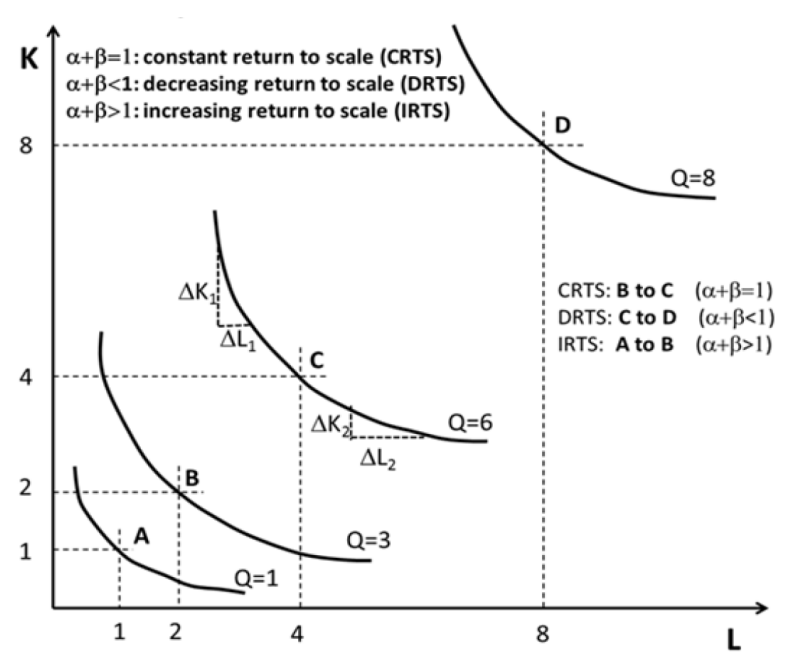

Fig. 1. Illustrative isoquant curves from CDPF

CDPF (Fig. 1) are very useful in explaining the origin of the crashing cost under many different situations.

An Isoquant (Varian 1992) is a contour line drawn through the set of points at which the same quantity of output is produced while changing the quantities of inputs. Figure 1 shows a set of isoquants for a production function with two inputs of capital $(K)$ and labor $(L) . K$ is equivalent to or interchangeable with equipment in this paper.

One important feature of CDPF is reflected by the summation value of $\alpha$ and $\beta$. When the summation of $\alpha$ and $\beta$ is less than 1 (DRTS) the double inputs of $L$ and $K$ will generate less than double output of Q. This is illustrated by case from point $\mathrm{C}$ to $\mathrm{D}$ in Figure 1. When the summation of $\alpha$ and $\beta$ is equal to 1 (CRTS) the double inputs of $L$ and $K$ will generate double output of $Q$, which is illustrated by case from point $B$ to $C$. When the summation of $\alpha$ and $\beta$ is greater than 1 (IRTS) the double inputs of $L$ and $K$ will generate more than double output of $Q$, which is illustrated by case from point A to $\mathrm{B}$.

In case that the production function is CRTS, it is introduced as:

$$
Q=(A L)^{1-\alpha} \cdot K^{\alpha} .
$$

Another important feature related to this study is the efficiency of substituting part of labor $(\Delta L)$ input for part of equipment input $(\Delta K)$. As we can see in the isoquant curve of $Q=6$, the efficiency of substituting $K$ for $L$ is decreasing (from $\Delta K_{1} \Delta L_{1}$ to $\Delta K_{2} \Delta L_{2}$ ) as more labor replacements are added to generate the same amount of $Q$, in this case $Q=6$.

Construction activity crashing can be achieved through increasing $A$, technology, or by increasing inputs of $L$ and/or $K$ in fixed period of time. In both cases the $Q$ will increase in unit time period, which is essentially activity crashing. In this paper, we limit our scope of crashing within the allocation of $L$ and $K$, while assuming construction technology $(A)$ is same during the crashing process. This will allow us to focus our discussions on how to best utilize $L$ and $K$ in crashing.
The authors believe CDPF provides a feasible tool to model construction schedule crashing activities, especially model the time-cost trade-off problem. The origin or source of the cost increase in construction TCTP can be theoretically explained using CDPF. The duration crashing is achieved through increase either $L$ or $K$ or both, so to increase $Q$ in a given time. The CDPF together with cost functions of both labor and equipment provide a potential way to incorporate detailed labor and equipment costs and utilization information into the timecost optimization model in construction TCTP.

To this end, in the paper, the authors discuss a new framework for TCTP in construction using CDPF and GA. A case study is presented using the proposed framework and the results are discussed. The authors believe the proposed CDPF framework for TCTP provide a new perspective for research in construction TCTP by enabling further analysis on optimizing labor and equipment allocations during the activity crashing process. This approach enable the project managers to further understand his options in allocating appropriate combinations of labor and equipment based on the CDPF. This additional capacity is a major contribution of this paper, which has not been reported in existing publications to our best knowledge.

\section{Related works}

Existing publications on construction TCTP can be classified based on various cost function they assumed, different solution method, different objective function assumed for the problems, models and solution methods.

\subsection{Construction crashing time-cost function}

The relation between cost and the time has been well studied in various researches. Cost functions such as linear (Bazaraa, Shetty 1979; Fulkerson 1961), nonlinear (Moussourakis, Haksever 2010), discrete (Kelly 1961; this research), convex (Lamberson, Hocking 1970; Demeulemeester et al. 1993), and concave (Berman 1964) have been implemented in the studies on TCTP hitherto.

\subsection{Objective function}

Objective function in construction crashing cost analysis may vary significantly. Some researchers consider multiobjective function and assume priority between time and cost, and base on that, they try to optimize the solution. Some consider minimizing total project cost. Some try to minimize total project cost or duration subject to predefined constraints.

Moussourakis and Haksever (2010) considered three objective functions include minimizing project completion subject to a crash budget constraint, minimizing total project cost, and minimizing total cost under late completion penalties. They used nonlinear time-cost functions.

Leu et al. (2001) tried to determine project completion time regarding project total cost which includes both direct and indirect cost. Some other authors 
consider a limited budget for the project and try to minimize the project duration under the budget constraints (Buddhakulsomsiri, Kim 2006).

Jaskowski and Sobotka (2006) proposed a multicriteria objective function which consider both time and cost together, and they end up with a Pareto set. They used an evolutionary algorithm to compare different solutions based on fitness values.

One of the main assumptions or constraints, which highly considered in the literature, is the limitation of resources. Jaskowski and Sobotka (2004) try to minimize the project completion time regarding the limitation on resources. They also proposed an evolutionary algorithm to assign recourses to activities in a proper time.

Some authors assume chose different approach to cope with this problem. To avoid delay in projects, Lin et al. (2011), based on historical data, for prediction of construction project completion time. They used regression model to forecast the future projects. Chen et al. (2011) developed a cash-payment model for forecasting the cash flow. They evaluated their model by comparing two historical real dataset.

\subsection{Models}

There are three main categories in existing literature regarding models or assumptions in time-cost trade-off problem: 1) Deterministic relation between time and cost was assumed in Gerk and Qassim (2008), Moussourakis and Haksever (2010), Pollack-Johnson and Liberatore (2006). 2) Stochastic relation between time and cost was assumed in Aghaie and Mokhtari (2009), Cohen et al. (2007), Ke et al. (2009). 3) Fuzzy relation between time and cost was assumed by Ghazanfari et al. (2009).

Gerk and Qassim (2008) considered both activity overlapping and substitution in their model. Pollack-Johnson and Liberatore (2006) assumed discrete time-cost trade-off activity like as we do in the following section. In both studies predefined budget were assumed. Moussourakis and Haksever (2010) assumed nonlinear time cost function which is more realistic than linear ones. Some other authors Diaby et al. (2011) took similar approach in terms of cost functions. They propose a geometric programming, and then try to solve it.

Aghaie and Mokhtari (2009) proposed a nonlinear mix integer programming to increase the probability of completion of the project in a given due date. They also assume that each activity duration follow an exponential distribution. Ke et al. (2009) proposed integrating stochastic simulation and genetic algorithm to increase the probability of completion of a project by the due date. Cohen et al. (2007) wanted to minimize the expected cost related by the project.

Ghazanfari et al. (2009) assumed fuzzy variables. Via Possibility Goal Programming the cost was minimized while considering the minimum duration. The main contribution of this fuzzy approach is the use of vagueness in cost function during the project execution.
Zheng and $\mathrm{Ng}$ (2005) also presented fuzzy set theory regarding the uncertainty included in TCTP problem. They also use GA as a meta-heuristic algorithm to develop a Pareto set between time and cost.

\subsection{Solution method}

Large-scale time-cost trade off problem is often NPhard. The methods developed to tackle this problem varied from exact approach such as dynamic programming (DP) (Robinson 1965) to heuristic and meta-heuristic algorithms. Yang (2007) proposed a particle swarm algorithm to complete the project for all kind of linear or nonlinear cost function, discrete or continuous, and concave or convex.

Feng et al. (1997) proposed a genetic algorithm to draw a Pareto set for a discrete time-cost trade-off. They consider a multi-objective criteria problem to find the optimal solution, which ended up with a Pareto set. Aghaie and Mokhtari (2009) proposed an ant colony optimization for stochastic crashing problem. They also assume a discrete time cost function problem. As stated earlier, they have assumed that the time-cost relationship is stochastic. So they also use Monte-Carlo simulation to cope with this problem.

One recent example of exact solution method for large-scale problems using benders decomposition-based exact algorithm is introduced by Hazir et al. (2010). Skutella (1998) proposed an approximation algorithm which is an effective algorithm for large scale problems. Metaheuristic algorithms have been introduced in the recent years even in other areas of construction project management. Zhang and Ng (2012) who used this kind of algorithm to develop DSS for TCTP, and Bozejko et al. (2012) was a good example for that.

The proposed approach of this paper and other recent related researches are summarized in Table 1, to provide a context of our contribution to this research domain.

\section{Time-cost model formation using Cobb-Douglas function}

In this paper, the amount of work need to be done for each activity is fixed and it is defined as workload $(W)$ for each activity. Activities with reducible duration are remarked as soft activities versus the hard activities with irreducible duration. When an activity is crashed (the time is shortened from normal duration), production output $Q$ is increased through the increased inputs of labor $(L)$ and/or equipment $(K)$.

Considering the production function of an activity as $Q=F(L, K)$, and normal time, $t_{0}$, then the production output rate to accomplish the activity is:

$$
Q_{0}=\frac{W}{t_{0}}
$$

where: $Q_{0}$ is the normal production output rate; $W$ is the total production output during $t_{0}$ duration. 
Table 1. Related works

\begin{tabular}{|c|c|c|c|c|c|c|c|c|c|c|}
\hline Authors & Cost function & Objective function & 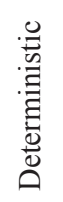 & 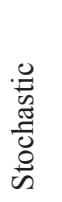 & 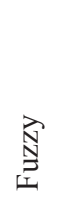 & 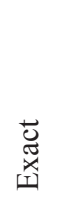 & 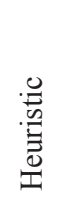 & 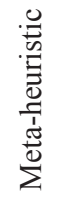 & 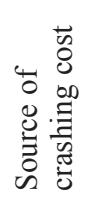 & - Approach \\
\hline Feng et al. (2000) & Discrete & Multi-objective & & & & $\vee$ & & $\vee$ & & GA-Simulation \\
\hline Zheng et al. (2004) & Discrete & Multi-objective & $\checkmark$ & & & & & $\checkmark$ & & GA \\
\hline $\begin{array}{l}\text { Zheng and } \mathrm{Ng} \\
(2005)\end{array}$ & Discrete & $\begin{array}{l}\text { Optimal balance of time } \\
\text { and cost }\end{array}$ & & & $\vee$ & & & $\vee$ & & Fuzzy set theory-GA \\
\hline $\begin{array}{l}\text { Pollack-Johnson and } \\
\text { Liberatore (2006) }\end{array}$ & Discrete & $\begin{array}{l}\text { Min project duration } \\
\text { considering quality }\end{array}$ & $\vee$ & & & & & & & Quality Management \\
\hline Cohen et al. (2007) & Linear & Completion by a due date & & $\mathrm{v}$ & & & & & & Robust optimization \\
\hline $\begin{array}{l}\text { Evansmo and } \\
\text { Karlsen (2008) }\end{array}$ & Linear & $\begin{array}{l}\text { Determine the impact of } \\
\text { labor cost on total project } \\
\text { cost }\end{array}$ & $\vee$ & & & & & & $\vee$ & - \\
\hline $\begin{array}{l}\text { Aghaie and } \\
\text { Mokhtari (2009) }\end{array}$ & $\begin{array}{l}\text { Non-linear } \\
\text { integer math. } \\
\text { Programming }\end{array}$ & $\begin{array}{l}\text { Completing the project by } \\
\text { a due date }\end{array}$ & & $\vee$ & & & & $\vee$ & & $\begin{array}{l}\text { Ant Colony Optimization } \\
\text { and MC Simulation }\end{array}$ \\
\hline Ke et al. (2009) & Discrete & Min expected cost & & $\vee$ & & & & $\vee$ & & $\begin{array}{l}\text { Chance constraint } \\
\text { optimization-GA }\end{array}$ \\
\hline $\begin{array}{l}\text { Ghazanfari et al. } \\
\text { (2009) }\end{array}$ & Non-linear & $\begin{array}{l}\text { Min crashing cost-min } \\
\text { duration }\end{array}$ & & & $\vee$ & & & & & $\begin{array}{l}\text { Possibility goal } \\
\text { programming }\end{array}$ \\
\hline $\begin{array}{l}\text { Moussourakis and } \\
\text { Haksever (2010) }\end{array}$ & Non-linear & $\begin{array}{l}\text { minimizing project } \\
\text { completion-minimizing } \\
\text { total project cost- } \\
\text { minimizing total cost } \\
\text { under late completion } \\
\text { penalties }\end{array}$ & $\vee$ & & & $\vee$ & & & & - \\
\hline Hazir et al. (2010) & Discrete & $\begin{array}{l}\text { minimizing project } \\
\text { completion considering } \\
\text { the budget }\end{array}$ & $\vee$ & & & $\vee$ & & & & Benders decomposition \\
\hline Diaby et al. (2011) & Non-linear & Project completion & $\vee$ & & & $\checkmark$ & & & & Geometric programming \\
\hline This research & Discrete & $\begin{array}{l}\text { Optimizing construction } \\
\text { crashing cost considering } \\
\text { labor and equipment cost }\end{array}$ & $\vee$ & & & $\vee$ & & $\vee$ & $\vee$ & $\begin{array}{l}\text { Hybrid Genetic } \\
\text { Algorithm \& } \\
\text { Cobb-Douglas Function }\end{array}$ \\
\hline
\end{tabular}

During crashing when duration was shortened to $t_{1}$ from $t_{0}$, the corresponding output becomes:

$$
Q_{1}=\frac{W}{t_{1}}
$$

where: $Q_{1}$ is the crashed production output rate; $t_{1}$ is the crashed duration.

Therefore, to reduce the activity duration by $t_{0}-t_{1}$, output is increased by $Q_{1}-Q_{0}$ per time unit, due to the extra inputs of labor and/or equipment. Although both CRTS and DRTS (for example, due to working space constraints) are possible scenarios, to simplify the discussion without compromising the main topic we limit our discursion in this paper to a CRTS scenario, in which $\alpha+\beta=1$ (Fig. 1).

Also we assume that technology $A$ is constant and equal to 1 for simplicity without affecting the results and conclusions, since the paper is concern with allocation of existing labor and equipment resources during crash- ing, not with introducing new technology into crashing. In most existing literature (Sircar, Choi 2007) technology changes were often measured (by changes of A) over long period of time, normally 5 to 20 years.

As discussed earlier, in this paper, we limit our concern to CRTS. In this case, according to Romer (2005), in order to eliminate the uncertainty caused by $A$, eliminate the impact of other resources such as land and other natural resources, Eqn (2) can be converted into the intensive form as follows:

$$
f(k)=k^{a},
$$
where $k$ is defined as $\frac{K}{A L} . k$ is capital per unit of effec-
tive labor.

$\alpha$ and $\beta$ are also known as the labor and capital's share of output which identify the contribution of labor and capital in total production. Different combinations of $\alpha$ and $\beta$ for different activities can be estimated by project managers based on the historical data, for example 
via regression method (Mateescu 2010). In many existing production research (Felipe, Adams 2005), $\alpha=0.3$, $\beta=0.7$ are often reported. Since the specific value of $A$, $\alpha$ and $\beta$ are treated as case parameters and will not affect the proposed overall framework. We assume $\alpha=0.7$ in intensive form of the function, then we get:

$$
f(k)=k^{0.7} .
$$

If $W=10000$ for this specific activity, and normal time $t_{0}=25$ days, then we have:

$$
Q_{0}=\frac{W}{t_{0}}=\frac{10000}{25}=400 .
$$

Accordingly, if the crashed duration $t_{1}$ and $t_{2}$ equal to 20 day and 16 days respectively, then we have:

$$
\begin{aligned}
& Q_{0}=\frac{W}{t_{1}}=\frac{10000}{20}=500 ; \\
& Q_{0}=\frac{W}{t_{2}}=\frac{10000}{16}=625 .
\end{aligned}
$$

The cost function of an activity is often defined as:

$$
T C=c_{1} L+c_{2} K,
$$

where: $T C$ - total cost of the activity; $c_{1}$ - salary rate; $L$ - labor input quantity; $c_{2}$ - equipment rental rate; $K$ - equipment input quantity; labor cost $L C=c_{1} L$; equipment cost $K C=c_{2} K$.

Eqn (9) can be illustrated by the isocost lines shown in Figure 2, in which lines $T C_{1}, T C_{2}$ and $T C_{3}$ are cost lines with same $r$ and $s$ values. The tangent points (such as points $\mathrm{A}$ and $\mathrm{B}$ ) between the isocost lines and the isoquant curves are the minimal cost of producing $Q=3$ (point A) and producing $Q=6$ (point B). The line connecting all the tangent points is referred as production expansion line, which represent the minimal cost solution to expand the production if the cost function $\left(c_{1}\right.$ and $c_{2}$ ) hold the same.

If we assume labor cost is 30 dollars per labor unit, capital cost is 90 dollars per equipment unit, Eqn (8) will become:

$$
T C=30 x_{1}+90 x_{2},
$$

where $x_{1}$ and $x_{2}$ represent $L$ and $K$, respectively.

Using $f_{0}, f_{1}$ and $f_{2}$ to derive isoquant curves and Eqn (10) to draw isocost lines, we can find the minimal total cost $\left(T C_{\min }\right)$ for $Q_{0}, Q_{1}$ and $Q_{2}$, in which $f_{0}$ represent production in a normal duration, and $f_{1}$ and $f_{2}$ represent production in the crashed durations (Fig. 3).

The results are: while $t_{\mathrm{i}}=\{25,20,16\} ; T C_{\mathrm{i} \min }=$ $\{848,1062,1314\}$ and $L C_{\mathrm{i}}, K C_{\mathrm{i}}=\{(477,371) ;(598$, $464) ;(739,575)\}$. The results are graphically shown in Figure 3, where straight lines represents isocosts from Eqn (10) and curve lines represent isoquants derived from

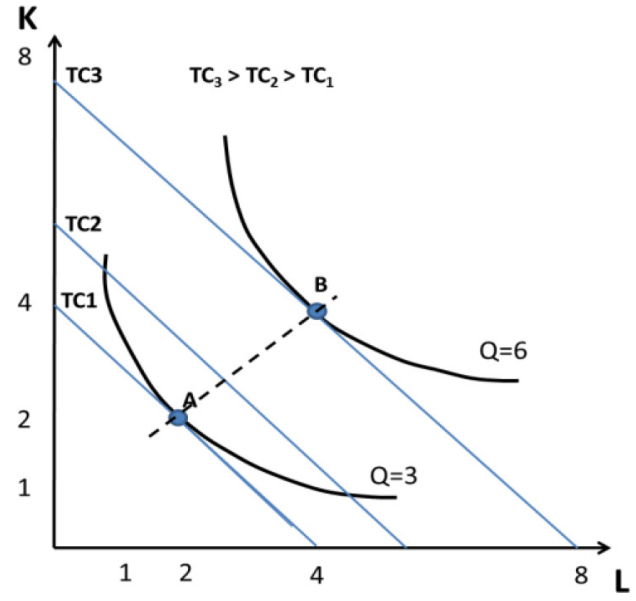

Fig. 2. The concept of isocost lines and the minimal cost of producing Q

CDPF with 3 different $f$ values. The $T C_{\min }$ for each duration (or $f$ ) is the tangent point of each isoquant curves.

Considering the total crashing cost for all activities in a network, the mathematical model to find combination of labor and equipment factors minimizing the total cost for all involved activities is represented as:

$$
\begin{array}{ll}
\text { Min } & c_{1 i} \times L_{i}+c_{2 i} \times K_{i} \\
\text { S.t. } & f(k)=k^{0.7} \quad \forall i \in S .
\end{array}
$$

In order to present a multi-objective function which contains cost and duration we define the objective function as:

$$
Z_{i}=w_{1} C_{i}+w_{2} T_{i},
$$

where $w_{1}$ and $w_{2}$ are defined based on the decision makers' preferences and $w_{1}+w_{2}=1 . C_{i}$ and $T_{i}$ are normalized scores of cost and duration respectively, and both have values from 0 to $1 . C_{i}$ and $T_{i}$ are defined as:

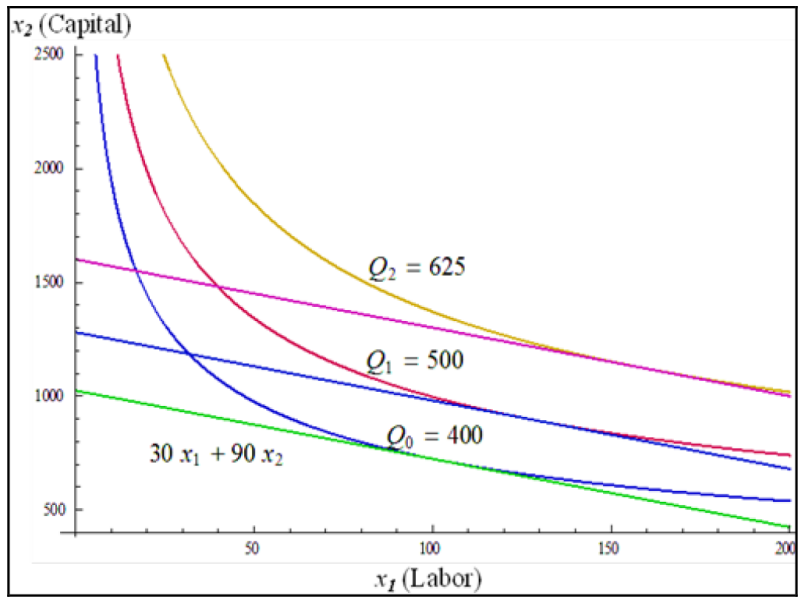

Fig. 3. A simple example of finding minimal activity cost using isocosts and isoquants 


$$
\begin{aligned}
C_{i} & =\frac{\max \text { Cost }-C_{\text {solution }}}{\max \text { Cost }-\min \text { Cost }} ; \\
T_{i} & =\frac{\max \text { Time }-T_{\text {solution }}}{\max \text { Time }-\min \text { Time }} .
\end{aligned}
$$

So the best score for either cost or duration is 1 , when the solution is the minimal. And the worst score is 0 , when the solution is maximal. The larger $Z$ values represent the better overall solutions.

\section{The proposed hybrid genetic algorithm (HGA)}

\subsection{GA background}

Genetic algorithm (GA) was developed by John Holland (1975). GA is a population based searching technique. Its main idea came from natural evolution. There are various hard optimization problems such as Travel Salesman Problem (TSP), job shop scheduling, covering etc., can be solved by genetic algorithm. GA, like other meta-heuristic algorithms, searches the whole space containing two conflicting operation exploring the whole space while trying to improve the quality of current solution in its neighborhood through finding the local optimum.

Genetic algorithm contains two main operations: crossover, and mutation. In the crossover phase, GA produces new offspring from two parents which are chosen from the population. The second operation in GA, which helps GA to search the all search space and not just looking for the local optimums, is mutation. GA like other artificial intelligence algorithms avoids trapping in local optimum solutions through its operation called mutation which will be explained later. The new generations are compared with the existing solutions; they may be replaced if they have a better fitness value.

\subsection{HGA background}

One of the main problems associated with GA is its initial solution in the population. Two main categories could be considered for this problem, first related to the population size which is usually determined by try and error, and according to Golberg (1989), it is normally between 30 and 500 . The other issue is the quality of chromosomes or initial solutions generated in population.

Hybrid genetic algorithms (HGA) (El-Mihoub et al. 2006) were proposed to overcome limitations of most meta-heuristic algorithms by adding local searches, adding learning methods, etc. (Revees 1994; Thierens et al. 1998) to make it more efficient. In this paper local search called 2-opt is used to overcome the mentioned problems. The 2-opt local search is expected to improve the randomly generated population solutions. 2-opt was first introduced in Croes (1958) as a local search in traveling salesman problem. Later, it is modified and used in other operation research applications (McGovern, Gupta 2003; Buffa et al. 1964) as an effective way to address the limitations of pure GA.

\subsection{The proposed HGA}

In this section, we present the proposed hybrid genetic algorithm for time-cost optimization problem. The proposed algorithm is depicted in detail in Figure 4. In the initialization phase, algorithm starts with randomly generated chromosomes based on population size (as an input). To avoid the generation problems, which is our main reason to use a hybrid algorithm, 2-opt procedure will improve the initial solutions, which will explain later more in depth later. To go through the GA, a selection procedure proposed, which chooses chromosomes to be transformed by GA based on their quality (fitness value).

As stated before, GA includes two main operations: crossover and mutation. After that, these two operations transform the solutions to get a better solution regarding fitness function. If the new solution is better than the current one it is substituted with the current solution (chromosome); otherwise it keep the current solution. Then the procedure starts again. It should be noted that a termination criteria presumed for the algorithm. When it meets the criteria, it would be stopped.

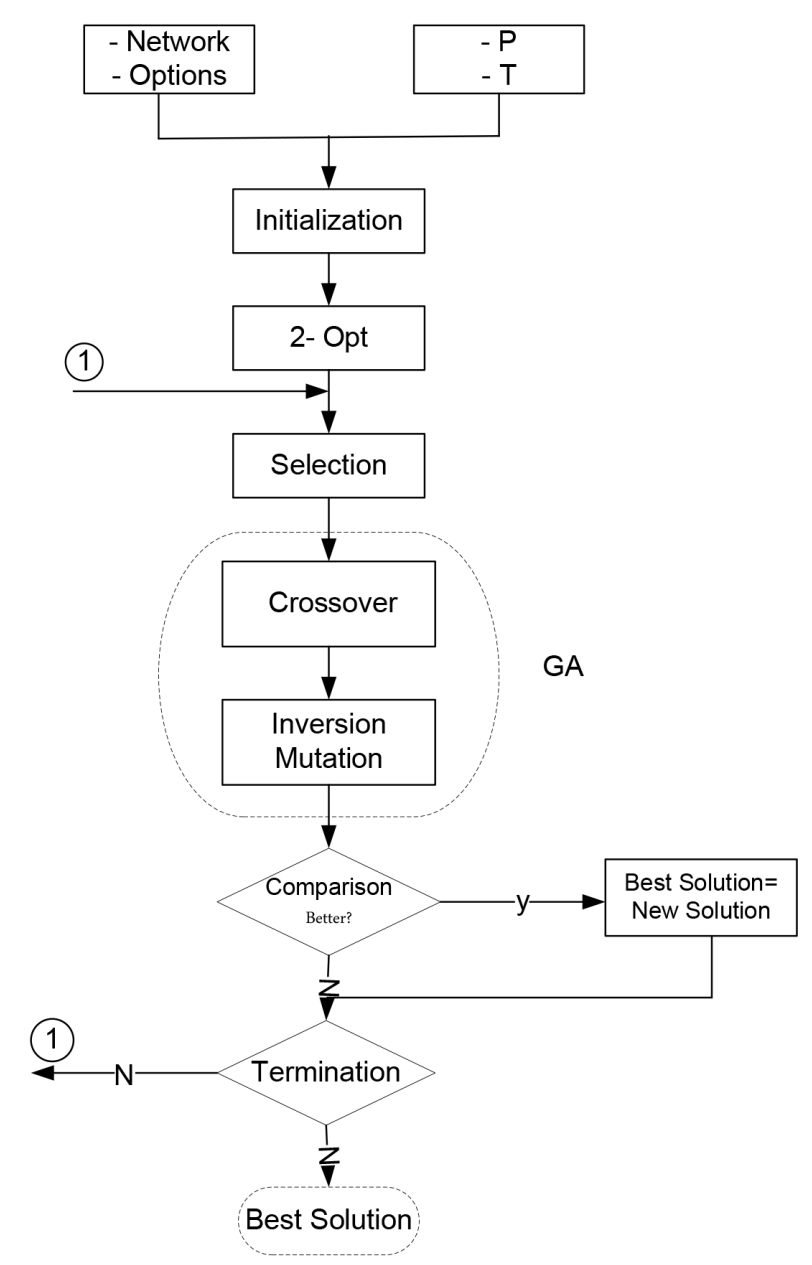

Fig. 4. The flowchart of HGA 


\subsubsection{Notations}

There are some notations that we need to define before developing a genetic algorithm:

- PS: Population size (which is usually defined based on the problem size);

- $T$ : Number of generation before termination;

- $Z_{i}$ : Objective value (fitness value) of solution $i^{t h}$. $P S$ and $T$ which are presented in Figure 4 as inputs of genetic algorithm. They are determined before the algorithm starts. Although, as discussed earlier, PS has an impact on the performance of genetic algorithm and may cause problem in case that it defined improperly, it defines mostly by try and error. It is the same story for defining $T$ as number of iteration must be implemented before the time that the algorithm is terminated. With try and error, it defines based on trade-off between run time and the efficiency of solutions.

In the proposed algorithm $P S$ is equal to 100 , and $T$ is assumed $300 . Z_{i}$ which will be used in different phases of the algorithm is the objective value or fitness value of a solution $i^{\text {th }} . Z_{i}$ is the basis for comparing the solutions.

\subsubsection{Initialization}

Regarding the $P S$, we generate chromosomes. Number of genes in each chromosome is equal to number of activities included in the project. For each activity (genes) a random number generated based on number of activities regarding the fact that we consider discrete form of timecost function in this study. So now, we have PS (population size) randomly generated chromosomes.

\subsubsection{Procedure of 2-opt}

In order to hybridize the genetic algorithm to work more efficiently, we use 2-opt which is a well-known algorithm among researchers. 2-opt, as stated, first developed by Croes (1958) for traveling salesman problem to change the order of arcs which are passed by salesman. After then, it is developed in other problems.

Here, for the second phase in the proposed HGA which works as an improvement phase for the initial solutions generated in the population, we develop a 2-opt procedure which generates all possible combination of two randomly selected genes and their neighborhoods. That is, for each chromosome (initial solution), it generates 5 offspring. In the first one, it just changes the positions of selected genes. After then, all possible swaps are checked. Although it increases the run time, it avoids the problems which caused by generating random population. Figure 5 shows the details of how 2-opt works.

Then, the fitness value of parent and offspring (all together would be at most 6 solutions) are compared and the best one will be replaced by the current solution (parent).

\subsubsection{Selection}

While in most articles in the literature, authors propose an algorithm which randomly selects the chromosomes from

\begin{tabular}{|ccccccccccccccccc|}
\hline Parent 1: & 4 & 4 & 1 & 3 & 2 & 4 & 3 & 2 & 2 & 2 & 3 & 4 & 1 \\
offspring 1: & 4 & 4 & 2 & 3 & 2 & 4 & 3 & 1 & 2 & 2 & 3 & 4 & 1 \\
offspring 2: & 4 & 2 & 4 & 3 & 2 & 4 & 3 & 1 & 2 & 2 & 3 & 4 & 1 \\
offspring 3: & 4 & 4 & 3 & 2 & 2 & 4 & 3 & 1 & 2 & 2 & 3 & 4 & 1 \\
offspring 4: & 4 & 4 & 2 & 3 & 2 & 4 & 1 & 3 & 2 & 2 & 3 & 4 & 1 \\
offspring 5: & 4 & 4 & 2 & 3 & 2 & 4 & 3 & 2 & 1 & 2 & 3 & 4 & 1 \\
\hline
\end{tabular}

Fig. 5. 2-opt algorithm

the population to do the GA operations on them (Zheng et al. 2004), chromosome selection from the population is based on their objective value (fitness value) in this study. Roulette wheel selection (Goldberg 1989) is applied here to come up with this drawback in the literature. First, it avoids that not only the best chromosome in the population selected. Second, it is not selected randomly. That is, the chromosome selection is proportional to their objective values. So, the better a chromosome is regarding its objective value, the more probability has to choose.

The roulette wheel selection method is summarized in the following steps:

Step 1: Calculate the total fitness of all chromosomes in the population:

$$
S=\sum_{i=1}^{P S} Z_{i}
$$

Step 2: Calculate the selection probability for each chromosome, which is proportional to the fitness value of that chromosome to total fitness of all chromosomes in the population:

$$
P_{i}=\frac{Z_{i}}{S} .
$$

Step 3: First, it should be noted that:

$$
\sum_{i=1}^{P S} P_{i}=1
$$

So, the summation of selection probabilities from the first chromosome to the $i^{\text {th }}$ chromosome is called cumulative probability. Calculate the cumulative probability for each chromosome:

$$
q_{i}=\sum_{j=1}^{i} p_{j}
$$

Step 4: generate $0<r \leq 1$.

Step 5: chromosome $i^{\text {th }}$ will be selected if $q_{i}<r \leq q_{i}$. The difference between $q_{i-1}$ and $q_{i}$ is $p_{i}$.

$$
q_{i}-q_{i-1}=p_{i}
$$

\subsubsection{The crossover}

The proposed crossover is the classical order crossover introduced by Gen and Cheng (1997). In the first step, it chooses two parents from the population randomly then does the required transformation on them to have new offspring. According to the fact that, each chromosome contains specific options for each activity, after 
choosing a substring in order to do crossover, the genes are exchanged to have new offspring. The procedure is as follows:

Step 1: Select a substring from the first parent randomly. Step 2: Produce an offspring by copying the substring into the corresponding positions in that.

Step 3: Place the genes other than the chosen substring from the first parent, into the unfilled positions of the offspring from left to right.

Step 4: Repeat Steps 1-3 to produce another offspring by exchanging the two parents.

Afterward, $Z_{i}$ s are compared to choose the better one between each offspring and the related parent. This process is shown in Figure 6.

\subsubsection{The inversion mutation}

There are various procedures are introduced for mutation in different research areas; one of those is inversion mutation. The inversion mutation firstly introduced by Gen and Cheng (1997). In this phase, a substring is randomly selected, and all included genes are flipping. As stated earlier, mutation operation is developed to exploit all over the search space to find the global optimum instead of looking for local optimum in the neighborhood of current solution. Inversion mutation is used to diversify the solution in the solution space, which should be done basically by a mutation operation. The inversion mutation procedure is shown in Figure 7.

\section{Case study}

A case study is presented in this section to demonstrate the application context of the proposed approach. The network has been chosen from (Liu et al. 1995) and is illustrated in Figure 8.

We adopted the duration options and the activity network from Liu's paper (Liu et al. 1995) for each activity. But we assigned estimated workload $(W)$ to each activity in order to use CDPF to better analyze best allocations of labor and equipment. We also identified typical unit costs for labor $\left(C_{L}\right)$ and equipment $\left(C_{K}\right)$ for each activity from RS Means Construction Cost

\begin{tabular}{ccccccccccccccc|}
\hline Parent 1: & 4 & 3 & 1 & 3 & 2 & 4 & 3 & 2 & 2 & 2 & 3 & 4 & 1 \\
Parent 2: & 3 & 3 & 2 & 1 & 2 & 3 & 1 & 3 & 4 & 2 & 4 & 3 & 2 \\
& & & & & & & & & & & & & \\
offspring 1: & 4 & 3 & 1 & 3 & 2 & 3 & 1 & 3 & 2 & 2 & 3 & 4 & 1 \\
offspring 2: & 3 & 3 & 2 & 1 & 1 & 4 & 3 & 2 & 4 & 2 & 4 & 3 & 2 \\
\hline
\end{tabular}

Fig. 6. The crossover

\begin{tabular}{cccccc|cccc|cccccc|}
\hline Parent 1: & 4 & 3 & 1 & 3 & 1 & 4 & 3 & 2 & 2 & 2 & 3 & 4 & 1 \\
& & & & & & & & & & & & & \\
offspring 1: & 4 & 3 & 1 & 3 & 2 & 3 & 4 & 1 & 2 & 2 & 3 & 4 & 1 \\
\hline
\end{tabular}

Fig. 7. The inversion mutation

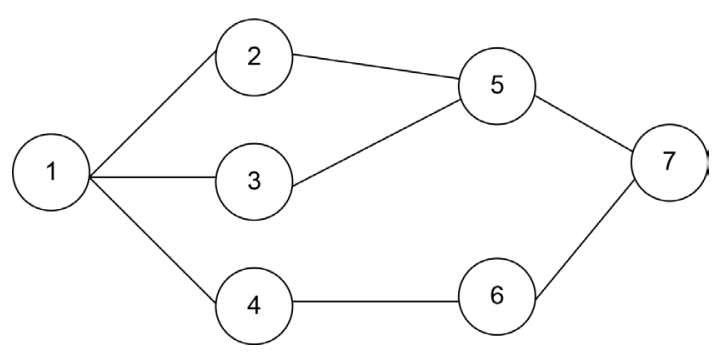

Fig. 8. The project network (Liu et al. 1995)

Data Book 2009. After knowing the $W$ for each activity, associated $Q$ of each of the three options are obtained using Eqn (2) and Eqn (3) as described in Section 2 of the paper.

Then, $L$ and $K$ (the amount of labor and equipment inputs respectively) are determined according to the cost minimization function constrained to Cobb-Douglas function, which is presented as Eqn (10) in Section 2. The assumption is $\alpha=0.7$. The total labor cost for each activity $(T L C)$ is obtained from $C_{L} \times L$; and the total equipment cost for each activity TKC is obtained from $C_{K} \times K$. Total cost (TC) is equal to the summation of $T L C$ and TKC. All data used in this case are presented in the Table 2.

\section{Results}

HGA is applied to data in Table 2 to find the optimum/ near optimum solution reflected by maximal $Z$ value. Then the solutions are compared with the optimum solution which is obtained from checking all possible combinations of activities' options. The HGA has been run for 10 times for each case, and in all case the result is the same as the optimum solution, which shows that it works properly.

Assuming the decision makers' priority (utility function) for time and cost is: $w_{1}=0.4$ and $w_{2}=0.6$, then the optimum solution is shown in Table 3 and the selected option of each activity is boxed in Table 2 .

The 83-day duration of the project is obtained from the critical path (using Fig. 8) of the optimal solution options. Total cost of the project is obtained from the summation of total cost of the selected option of each activity in the optimal solution, which is equal $\$ 128,523$ (see Table 2 for details of the selected option in each activity) including both labor $(\$ 5,458.8)$ and equipment (\$12737.3) costs.

Objective value of this solution is calculated using Eqns (12), (13), and (14) as follows:

$$
\begin{aligned}
C= & \frac{\max \text { Cost }- \text { Csolution }}{\max \text { Cost }-\min \text { Cost }}=\frac{\$ 203243.32-\$ 128523.41}{\$ 203243.32-\$ 121207.38}= \\
& \frac{\$ 74719.92}{\$ 82035.95}=0.9108 ; \\
T= & \frac{\max \text { Time }- \text { Csolution }}{\max \text { Time }- \text { min Time }}=\frac{83-60}{103-60}=\frac{23}{43}=0.5348 .
\end{aligned}
$$


Table 2. The case project information

\begin{tabular}{|c|c|c|c|c|c|c|c|c|c|c|c|}
\hline Activity & Option & $W$ & $T$ (day) & $Q$ & $C L(\$)$ & $C K(\$)$ & $L$ & $K$ & $T C(\$)$ & $T L C(\$)$ & $T K C(\$)$ \\
\hline 1 & 1 & 5000 & 14 & 357.1 & 40 & 100 & 374.8 & 349.8 & 49975.3 & 14992.6 & 34982.7 \\
\hline 1 & 2 & 5000 & 20 & 250.0 & 40 & 100 & 262.4 & 244.9 & 34982.7 & 10494.8 & 24487.9 \\
\hline 1 & 3 & 5000 & 24 & 208.3 & 40 & 100 & 218.6 & 204.1 & 29152.2 & 8745.7 & 20406.6 \\
\hline 2 & 1 & 500 & 15 & 33.3 & 50 & 70 & 23.3 & 38.9 & 3885.4 & 1165.6 & 2719.8 \\
\hline 2 & 2 & 500 & 18 & 27.8 & 50 & 70 & 19.4 & 32.4 & 3237.8 & 971.4 & 2266.5 \\
\hline 2 & 3 & 500 & 20 & 25.0 & 50 & 70 & 17.5 & 29.1 & 2914.0 & 874.2 & 2039.8 \\
\hline 3 & 1 & 600 & 15 & 40.0 & 45 & 80 & 33.1 & 43.4 & 4960.0 & 1488.0 & 3472.0 \\
\hline 3 & 2 & 600 & 22 & 27.3 & 45 & 80 & 22.5 & 29.6 & 3381.8 & 1014.5 & 2367.3 \\
\hline 3 & 3 & 600 & 33 & 18.2 & 45 & 80 & 15.0 & 19.7 & 2254.5 & 676.4 & 1578.2 \\
\hline 4 & 1 & 6000 & 12 & 500.0 & 75 & 70 & 263.3 & 658.2 & 65819.1 & 19745.7 & 46073.4 \\
\hline 4 & 2 & 6000 & 16 & 375.0 & 75 & 70 & 197.5 & 493.6 & 49364.3 & 14809.3 & 34555.0 \\
\hline 4 & 3 & 6000 & 20 & 300.0 & 75 & 70 & 158.0 & 394.9 & 39491.5 & 11847.5 & 27644.1 \\
\hline 5 & 1 & 4500 & 22 & 204.5 & 60 & 60 & 113.0 & 263.7 & 22606.6 & 6782.0 & 15824.6 \\
\hline 5 & 2 & 4500 & 24 & 187.5 & 60 & 60 & 103.6 & 241.8 & 20722.8 & 6216.8 & 14505.9 \\
\hline 5 & 3 & 4500 & 28 & 160.7 & 60 & 60 & 88.8 & 207.2 & 17762.4 & 5328.7 & 12433.7 \\
\hline 6 & 1 & 5500 & 14 & 392.9 & 55 & 20 & 106.9 & 686.2 & 19604.7 & 5881.4 & 13723.3 \\
\hline 6 & 2 & 5500 & 18 & 305.6 & 55 & 20 & 83.2 & 533.7 & 15248.1 & 4574.4 & 10673.7 \\
\hline 6 & 3 & 5500 & 24 & 229.2 & 55 & 20 & 62.4 & 400.3 & 11436.1 & 3430.8 & 8005.2 \\
\hline 7 & 1 & 4700 & 9 & 522.2 & 65 & 30 & 168.0 & 849.2 & 36392.3 & 10917.7 & 25474.6 \\
\hline 7 & 2 & 4700 & 15 & 313.3 & 65 & 30 & 100.8 & 509.5 & 21835.4 & 6550.6 & 15284.8 \\
\hline 7 & 3 & 4700 & 18 & 261.1 & 65 & 30 & 84.0 & 424.6 & 18196.1 & 5458.8 & 12737.3 \\
\hline $\begin{array}{l}\text { Optimum } \\
\text { Solution }\end{array}$ & & & 83 & & & & & & 128522.9 & 38556.9 & 89966.1 \\
\hline
\end{tabular}

TC: total cost; TLC: total labor cost; TKC: total capital cost; T: duration options; Q: production quantity.

Table 3. Optimal solution options

\begin{tabular}{cccccccc}
\hline Activity & 1 & 2 & 3 & 4 & 5 & 6 & 7 \\
\hline Option & 3 & 1 & 1 & 3 & 3 & 3 & 2 \\
\hline
\end{tabular}

Max and min of cost of the project obtained by assigning the options with max cost and min cost to all activities respectively. The same story is true for max and min time. As stated earlier, when $w_{1}=0.4$, and $w_{2}=0.6$, the objective value is calculated as:

$$
\begin{aligned}
Z_{i}= & w_{1} T_{i}+w_{2} C_{i}=0.4 \times 0.9108+0.6 \times 0.5348= \\
& 0.5157 .
\end{aligned}
$$

Figure 9 illustrates all possible solutions. In case we do not consider utility function (priority) for time and cost, a Pareto set could be drawn like Figure 9. For example, in this specific case, if we do not assume any specific preference of $w_{1}$ and $w_{2}$, then the solution varied on the dash line in Figure 7. All the possible solutions on this line do not dominate the other ones; but when we assume some values for $w_{1}$ and $w_{2}$ we have just one answer based on $w_{1}$ and $w_{2}$ priorities. Pareto set optimality have been used extensively by authors in different aspects of construction project management. Jiang et al. (2011) have used Pareto set for cash flow planning in construction project management. They develop a multi objective cash flow consists of cash balance and interest paid to have a Pareto set.

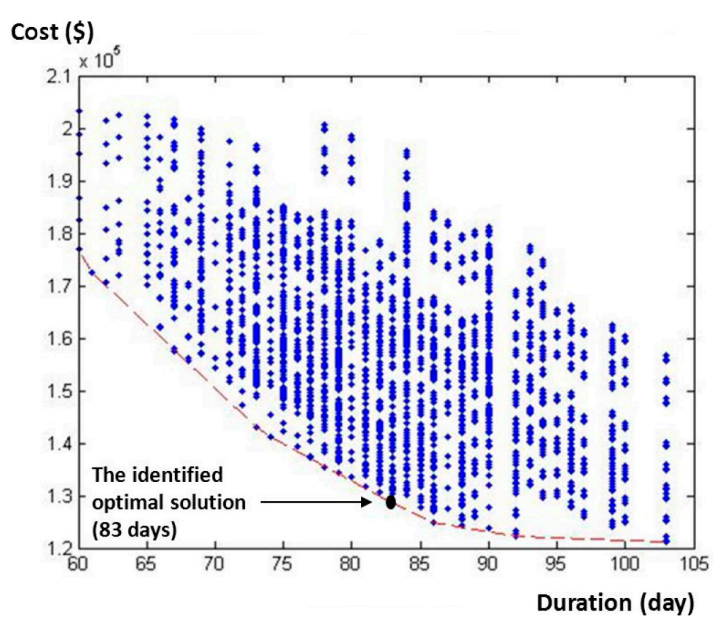

Fig. 9. All possible solutions

Figure 10 depicts how changes of $w_{1}$ (and also $w_{2}$ since $w_{2}=1-w_{1}$ ) affect the objective $Z$ values. As expected either $w_{1}$ or $w_{2}$ becomes $1, Z$ value would be 1 since only criteria need to be satisfied. When the decision maker weight time and cost equally in his decision making, $Z$ value is at the lowest point. So the optimal solution identified using HGA will depends on the decision maker's preference of time or cost. 


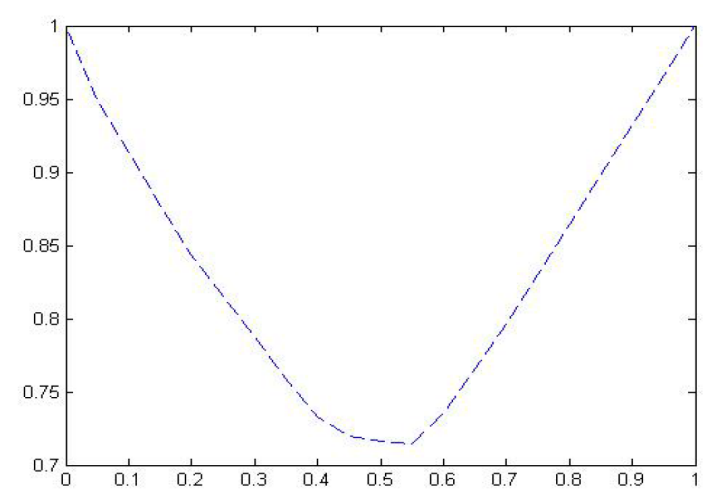

$w_{1}$

Fig. 10. Trend of $Z$ considering $w_{1}$ and $w_{2}$

Using this proposed approach, not only we obtain the optimal objective value, but also we understand clearly what the respective allocations of labor and equipment resources are. This will provide us with much needed capacity in TCTP to better evaluate all the possible resource allocation scenarios.

\section{Conclusions and future study}

A framework using Cobb-Douglas production function (CDPF) to solve construction time-cost trade-off problem (TCTP) is proposed in this paper. Within the framework, a multi-objective optimization method utilizing Hybrid Genetic Algorithm is presented with a case application. A significant advantage of introducing CDPF into TCTP is that CDPF can be used to quantitatively explain the origin of the crashing costs from both labor and equipment perspective, which was a fundamental gap in previous research on TCTP.

The results suggested that, by tying CDPF to TCTP, the proposed approach is capable to identify optimal labor and equipment allocation solution effectively to satisfy the need for duration reduction.

Although the presented case application is simple, the proposed approach is expected to work efficiently in larger and more complex applications. In future study, stochastic approach can be used with respect to uncertainties of $\alpha$ and $\beta$ in the CDPF, and uncertainties of the cost function of labor and equipment inputs.

\section{References}

Aghaie, A.; Mokhtari, H. 2009. Ant colony optimization algorithm for stochastic project crashing problem in PERT network using MC simulation, International Journal of Advanced Manufacturing Technology 45(11/12): 10511067. http://dx.doi.org/10.1007/s00170-009-2051-6

Banker, R. D.; Natarajan, R. 2008. Evaluating contextual variables affecting productivity using data envelopment analysis, Operations Research 56(1): 48-58. http://dx.doi.org/10.1287/opre.1070.0460

Bazaraa, M.; Shetty, B. 1979. Nonlinear programming theory and algorithms. $5^{\text {th }}$ ed. New York: Wiley. $560 \mathrm{p}$.

Berman, E. 1964. Resource allocation in a PERT network under continuous activity time-cost function, Management Science 10(4): 734-745.

http://dx.doi.org/10.1287/mnsc.10.4.734
Bozejko, W.; Hejducki, Z.; Wodecki, M. 2012. Applying metaheuristic strategies in construction project management, Journal of Civil Engineering and Management 18(5): 621630. http://dx.doi.org/10.3846/13923730.2012.719837

Buddhakulsomsiri, J.; Kim, D. S. 2006. Properties of multimode resource-constrained project scheduling problems with resource vacations and activity splitting, European Journal of Operational Research 175(1): 279-295. http://dx.doi.org/10.1016/j.ejor.2005.04.030

Buffa, E. S.; Armour, G. C.; Vollmann, T. E. 1964. Allocating facilities with CRAFT, Harvard Business Review, $136-158$.

Chen, H. L.; Chen, W. T.; Wei, N. C. 2011. Developing a costpayment coordination model for project cost flow forecasting, Journal of Civil Engineering and Management 17(4): 494-509. http://dx.doi.org/10.3846/13923730.2011.604540

Cobb, C. W.; Douglas, P. H. 1928. A theory of production, The American Economic Review 18(1): 139-165.

Cohen, I.; Golany, B.; Shtub, A. 2007. The stochastic time-cost tradeoff problem: a robust optimization approach, Networks 49(2): 175-188. http://dx.doi.org/10.1002/net.20153

Croes, G. A. 1958. A method for solving traveling salesman problem, Operations Research 6(6): 791-812. http://dx.doi.org/10.1287/opre.6.6.791

Demeulemeester, E.; Herroelen, W.; Elmaghraby, S. 1993. Optimal procedures for the discrete time-cost trade-off problem in project networks. Research Report. Department of Applied Economics, Katholieke Universiteit Leuven, Leuven, Belgium.

Dennis, E.; Gordon, B.; Sieg, H. 2010. A new approach to estimating the production function for housing, American Economic Review 100(3): 905-924. http://dx.doi.org/10.1257/aer.100.3.905

Diaby, M.; Cruz, J. M.; Nsakanda, A. L. 2011. Project crashing in the presence of general non-linear activity time reduction costs, International Journal of Operational Research 12(3): 318-332. http://dx.doi.org/10.1504/IJOR.2011.042919

El-Minhoub, T. A.; Hopgood, A. A.; Nolle, L.; Battersby, A. 2006. Hybrid genetic algorithm: a review, Engineering Letters 13(2): 1-14.

Evensmo, J.; Karlsen, J. T. 2008. Looking for the source where do crash costs come from?, Cost Engineering 50(7): 20-23.

Felipe, J.; Adams, G. F. 2005. "A theory of production" the estimation of the Cobb-Douglas function: a retrospective view, Eastern Economic Journal 31(3): 427-445.

Feng, C.; Liu, L.; Burns, S. 1997. Using genetic algorithms to solve construction time-cost trade-off problems, Journal of Computing in Civil Engineering 11(3): 184-189.

http://dx.doi.org/10.1061/(ASCE)0887-3801(1997)11:3(184)

Feng, C.; Liu, L.; Burns, S. 2000. Stochastic construction timecost trade-off analysis, Journal of Computing in Civil Engineering 14(2): 117-126.

http://dx.doi.org/10.1061/(ASCE)0887-3801(2000)14:2(117)

Fulkerson, D. 1961. A network flow computation for project cost curves, Management Science 7(2): 167-178. http://dx.doi.org/10.1287/mnsc.7.2.167

Gen, M.; Cheng, R. 1997. Genetic algorithms and engineering design. New York: John Wiley \& Sons, Inc. 411 p.

Gerk, J. E. V.; Qassim, R. Y. 2008. Project acceleration via activity crashing, overlapping, and substitution, IEEE Transactions on Engineering Management 55(4): 590-601. http://dx.doi.org/10.1109/TEM.2008.927786

Ghazanfari, M.; Yousefli, A.; Jabal Ameli, M. S.; Bozorgi-Amiri, A. 2009. A new approach to solve time-cost trade-off problem with fuzzy decision variables, International Journal of Advanced Manufacturing Technology 42(3-4): 408-414. http://dx.doi.org/10.1007/s00170-008-1598-y 
Goldberg, D. E. 1989. Genetic algorithms in search, optimization and machine learning. New York: Addison-Wesley. $412 \mathrm{p}$.

Hegazy, T. 1999. Optimization of construction time-cost tradeoff analysis using genetic algorithms, Canadian Journal of Civil Engineering 26(6): 685-697. http://dx.doi.org/10.1139/199-031

Hazir, O.; Haouari, M.; Erel, E. 2010. Discrete time/cost trade-off problem: a decomposition-based solution algorithm for the budget version, Computers and Operations Research 37(4): 640-655. http://dx.doi.org/10.1016/j.cor.2009.06.009

Holland, J. H. 1975. Adaptation in natural and artificial systems. Ann Arbor, Michigan, US: University of Michigan Press. 183 p.

Jaskowski, P.; Sobotka, A. 2004. Scheduling construction project with resource accessibility limited and changeable in time, Journal of Civil Engineering and Management 10(4): 267-276. http://dx.doi.org/10.1080/13923730.2004.9636319

Jaskowski, P.; Sobotka, A. 2006. Multicriteria construction project scheduling method using evolutionary algorithm, $O p$ erational Research, International Journal 6(3): 283-297.

Jiang, A.; Issa, R. A. A.; Malek, M. 2011. Construction project cash flow planning using the Pareto optimality efficiency network model, Journal of Civil Engineering and Management 17(4): 510-519. http://dx.doi.org/10.3846/13923730.2011.604537

Mateescu, G. D. 2010. On the implementation and use of a genetic algorithm with genetic acquisitions, Romanian Journal of Economic Forecasting 2: 223-230.

McGovern, S. M.; Gupta, S. M. 2003. 2-opt heuristic for the disassembly line balancing problem, in Proceedings of the SPIE International Conference on Environmentally Conscious Manufacturing III, 29-30 October 2003, Providence, Rhode Island, 71-84.

Meeusen, W.; Van Den Broeck, J. 1977. Efficiency estimation from Cobb-Douglas production functions with composed error, International Economic Review 18(2): 435-444. http://dx.doi.org/10.2307/2525757

Moussourakis, J.; Haksever, C. 2010. Project compression with nonlinear cost functions, Journal of Construction Engineering and Management 136(2): 251-259. http://dx.doi.org/10.1061/(ASCE)CO.1943-7862.0000123

Ng, S.; Zhang, Y. 2008. Optimizing construction time and cost using ant colony optimization approach, Journal of Construction Engineering and Management 134(9): 721-728. http://dx.doi.org/10.1061/(ASCE)0733-9364(2008)134:9(721)

Ke, H.; Ma, W.; Ni, Y. 2009. Optimization models and a GAbased algorithm for stochastic time-cost trade-off problem, Applied Mathematics and Computation 215(1): 308-313. http://dx.doi.org/10.1016/j.amc.2009.05.004

Kelly, J. 1979. Critical path planning and scheduling: mathematical basis, Operations Research 9(3): 296-320. http://dx.doi.org/10.1287/opre.9.3.296

Lamberson, L.; Hocking, R. 1970. Optimum time compression in project scheduling, Management Science 16(10): 597-606. http://dx.doi.org/10.1287/mnsc.16.10.B597

Leu, S. S.; Chen, A. T.; Yang, C. H. 2001. A GA-based fuzzy optimal model for construction time-cost tradeoff, International Journal of Project Management 19(1): 47-58.

http://dx.doi.org/10.1016/S0263-7863(99)00035-6
Lin, M. C.; Tserng, H. P.; Ho, S. P.; Young, D. L. 2011. Developing a construction-duration model based on a historical dataset for building project, Journal of Civil Engineering and Management 17(4): 529-539. http://dx.doi.org/10.3846/13923730.2011.625641

Liu, L.; Burns, S.; Feng, C. 1995. Construction time-cost trade-off analysis using LP/IP hybrid method, Journal of Construction Engineering and Management 121(4): 446-454.

http://dx.doi.org/10.1061/(ASCE)0733-9364(1995)121:4(446)

Pendharkar, P. C.; Rodger, J. A.; Subramanian, G. H. 2008. An empirical study of the Cobb-Douglas production function properties of software development effort, Information and Software Technology 50(12): 1181-1188. http://dx.doi.org/10.1016/j.infsof.2007.10.019

Pollack-Johnson, B.; Liberatore, M. L. 2006. Incorporating quality consideration into project time/cost tradeoff analysis and decision making, IEEE Transaction on Engineering Management 53(4): 534-542. http://dx.doi.org/10.1109/TEM.2006.883705

Reeves, C. 1994. Genetic algorithms and neighborhood search, Lecture Notes in Computer Science 865: 115-130. http://dx.doi.org/10.1007/3-540-58483-8 10

Robinson, D. R. 1965. A dynamic programming solution to cost-time trade-off for CPM, Management Science 22(2): 158-166. http://dx.doi.org/10.1287/mnsc.22.2.158

Romer, D. 2005. Advanced macroeconomics. $3^{\text {rd }}$ ed. Whitby: McGraw-Hill Ryerson Ltd.

Sircar, S.; Choi, J. 2009. A study of the impact of Information Technology on firm performance: a flexible production function approach, Information Systems Journal 19(3): 313-339. http://dx.doi.org/10.1111/j.1365-2575.2007.00274.x

Skutella, M. 1998. Approximation algorithm for the discreet time-cost trade-off problem, Mathematics of Operations Research 23(4): 909-929. http://dx.doi.org/10.1287/moor.23.4.909

Thierens, D.; Goldberg, D.; Guimaraes, P. 1998. Domino convergence, drift, and the temporal-salience structure of problems, IEEE International Conference on Evolutionary Computation, 4-9 May 1998, Anchorage, USA, 535-540.

Varian, H. R. 1992. Microeconomic analysis. $3^{\text {rd }}$ ed. New York: W. W. Norton \& Company Inc. 563 p.

Yang, T. 2007. Impact of budget uncertainty on project time-cost trade-off, Engineering Management 52(2): $167-174$

Zhang, Y.; Ng, S. T. 2012. An ant colony system based decision support system for construction time-cost optimization, Journal of Civil Engineering and Management 18(4): 580-589. http://dx.doi.org/10.3846/13923730.2012.704164

Zheng, D. X. M.; Ng, S. T.; Kumaraswamy, M. M. 2004. Applying a Genetic Algorithm-based multi-objective approach for time-cost optimization, Journal of Construction Engineering and Management 130(2): 168-176.

http://dx.doi.org/10.1061/(ASCE)0733-9364(2004)130:2(168)

Zheng, D. X. M.; Ng, S. T. 2005. Stochastic time-cost optimization model incorporating fuzzy sets theory and nonreplaceable front, Journal of Construction Engineering and Management 131(2): 176-186.

http://dx.doi.org/10.1061/(ASCE)0733-9364(2005)131:2(176) 
Zhigang SHEN. Visiting Associate Professor of Civil and Urban Engineering at Polytechnic School of Engineering of New York University; Associate Professor of Construction Management in the College of Engineering at the University of Nebraska-Lincoln. His main research interests are energy efficient building design and construction, virtual built environment, and virtual learning and training in design and construction. In his research areas he received multiple research grants sponsored by US federal agencies such as NSF, EPA, DOL and DOE.

Ashkan HASSANI. Graduate student of Construction Management in the College of Engineering at the University of NebraskaLincoln.

Qian SHI. Professor of School of Economics and Management at Tongji University. He is also the Director of the Center for Master of Engineering, School of Economics and Management, and the Vice-Chairman of the project management division of the Shanghai Society of Civil Engineers. His research mainly focuses on sustainable construction, project management, green building and risk management. 